\section{Eating patterns in the Brazilian Longitudinal Study of Adult Health (ELSA-Brasil): an exploratory analysis}

\author{
Padrões alimentares no Estudo Longitudinal de \\ Saúde do Adulto (ELSA-Brasil): \\ uma análise exploratória
}

\author{
Patrones alimenticios en el Estudio Longitudinal de \\ Salud del Adulto (ELSA-Brasil): \\ un análisis exploratorio
}

Letícia de Oliveira Cardoso ${ }^{1}$ Marilia Sá Carvalho 2 Oswaldo Gonçalves Cruz ${ }^{2}$ Cristiane Melere 3

Vivian Cristine Luft 3 Maria del Carmen Bisi Molina 4 Carolina Perim de Faria 4 Isabela M. Benseñor 5 Sheila Maria Alvim Matos 6 Maria de Jesus Mendes da Fonseca ${ }^{1}$ Rosane Harter Griep 7 Dóra Chor 1

\begin{abstract}
The food consumption of 15,071 public employees was analyzed in six Brazilian cities participating in the baseline for Brazilian Longitudinal Study of Adult Health (ELSA-Brasil, 2008-2010) with the aim of identifying eating patterns and their relationship to socio-demographic variables. Multiple correspondence and cluster analysis were applied. Four patterns were identified, with their respective frequencies: "traditional" (48\%); "fruits and vegetables" (25\%); "pastry shop" (24\%); and "diet/light" (5\%) The "traditional" and "pastry shop" patterns were more frequent among men, younger individuals, and those with less schooling. "Fruits and vegetables" and "diet/light" were more frequent in women, older individuals, and those with more schooling. Our findings show the inclusion of new items in the "traditional" pattern and the appearance of the "low sugar/low fat" pattern among the eating habits of Brazilian workers, and signal socio-demographic and regional differences.
\end{abstract}

Feeding Behavior; Urban Population; Multivariate Analysis; Adult

\footnotetext{
1 Escola Nacional de Saúde Pública Sergio Arouca

Fundação Oswaldo Cruz, Rio de Janeiro, Brasil.

2 Programa de Computação

Científica, Fundação

Oswaldo Cruz, Rio de Janeiro,

Brasil.

3 Faculdade de Medicina,

Universidade Federal do Rio

Grande do Sul, Porto Alegre,

Brasil.

4 Centro de Ciências da

Saúde, Universidade Federal

do Espírito Santo, Vitória,

Brasil.

5 Hospital Universitário,

Universidade de São Paulo,

São Paulo, Brasil.

6 Instituto de Saúde Coletiva

Universidade Federal da

Bahia, Salvador, Brasil.

7 Instituto Oswaldo Cruz,

Fundação Oswaldo Cruz, Rio

de Janeiro, Brasil.
} 


\section{Introduction}

Obesity, a leading health problem in many countries around the world, is very difficult to reverse. Dietary interventions based exclusively on energy intake and nutrients may yield immediate success, but fail in the medium and long term 1 . The current proposed dietary guidelines for the Brazilian population ${ }^{2}$, designed to promote a healthy diet in the Brazilian context and encouraging the consumption of "real food" (i.e. foods in their natural state or with minimal processing), constitute a new strategy for future interventions. However, it is fundamentally important to verify what Brazilian adults are eating today - not with a view to adjusting recommendations on nutrient intake in the strict sense, but to identify what foods are in fact being consumed, so as to suit the proposals of the guide to the realities of people's actual diets.

International organizations have encouraged the study of dietary patterns 3 to evaluate a population's overall diet. Dietary patterns are preferred over isolated nutrients, because studying specific compounds can attenuate the strength or prevent the identification of possible associations between overall diet and the risk of chronic disease ${ }^{4}$. Furthermore, identifying dietary patterns can help to establish new interventions, because they show how foods are combined into a dietary routine 5 .

Eating habits are changing in Brazil, as in other countries: consumption of ultra-processed and ready-to-serve foods is increasing, while consumption of minimally-processed and raw foods is decreasing, with adverse effects on health, as already indicated 6,7 . There is evidence that patterns of food consumption vary with demographic characteristics and socioeconomic levels. In Brazil, there are few studies relating to these dietary patterns. They are expected to be varied, given the country's cultural and economic diversity 5,8,9,10,11,12.

A recent study, representative of Brazil's population, revealed that household acquisition of food is characterized, at the same time, by foods acknowledged to be beneficial to health (e.g. fruit and vegetables) and less healthy foods (e.g. confectionery, processed meats, ready meals), and also by a "traditional" pattern that includes rice, beans, eggs, roots and tubers 13.

The Brazilian Longitudinal Study of Adult Health (ELSA-Brasil) evaluated food consumption in six cities in three of Brazil's macro-regions (Northeast, Southeast and South). It thus offers an excellent opportunity to pursue in-depth knowledge of dietary patterns among Brazilian working populations residing in large cities - particularly to explore the different patterns by socio-demographic characteristics.

\section{Materials and methods}

\section{Study population}

ELSA-Brasil is a multicenter cohort study that, at baseline (2008-2010), examined 15,105 civil servants at teaching and research institutions in six cities in Brazil 14,15. Its main purpose was to estimate the incidence of cardiovascular diseases and diabetes and their social, environmental, occupational and biological determinants. All of the six institutions' active and retired civil servants aged 35 to 74 were eligible for the study. Baseline evaluation lasted about 7 hours and was divided into two stages that included interviews and examinations conducted by a trained team. The interviews addressed sets of risk factors for the diseases of interest, as well as diet 16. Quality control measures included direct team supervision, testretest studies and centralized interpretation of laboratory and other test results 17 . The study was approved by the ethics committees of all six institutions and by the Brazilian National Research Ethics Committee and all participants signed a declaration of free and informed consent.

This study included 15,071 (99.8\%) ELSA-Brasil participants for whom complete information was available from the food frequency questionnaire (missing data $\mathrm{n}=29$ ) and on other study variables (missing data $\mathrm{n}=34$ ).

\section{Measuring food consumption}

A Food Frequency Questionnaire (FFQ) of 114 food items, based on a previously validated questionnaire 18 , was applied by trained interviewers, in order to evaluate participants' usual consumption in the previous 12 months. The list of foods was modified on the basis of a study performed at the six research centers in which 100 24-hour dietary recalls (R24h) were applied 19. Some foods (e.g. zucchini, chayote and eggplant) were grouped into single items. When different types of the same food displayed different nutritional features (e.g. white or whole rice; fullcream, semi-skimmed or skimmed milk), participants were asked to indicate which type they consumed most often, and only that one was recorded. The results of the quality evaluation studies of the ELSA-Brasil food frequency questionnaire demonstrated satisfactory reliability for all nutrients and acceptable relative validity for energy, macronutrients, calcium, potassium and vitamin $\mathrm{E}$ and $\mathrm{C} 20$. 
The semi-quantitative food frequency questionnaire of the ELSA-Brasil study was structured as follows: (1) foods/preparations; (2) number of portions, expressed in household measures or reference units; and (3) consumption frequencies ("more than 3 times a day", "2-3 times a day", "once a day", "5-6 times a week", "2-4 times a week”, “once a week”, “1-3 times a month” and "never/almost never"). Participants were asked about their consumption of each food item in the 12 months preceding the interview. In order to facilitate their choices, participants were offered a response card with consumption frequency options, eliminating the need to memorize them 19 .

\section{Statistical analysis}

\section{- Definition of food groups and frequency categories}

The 114 food items were assembled into ten groups by nutritional composition and by divisions used in previous studies in Brazil 18,21.

Initial analyses using the original eight FFQ categories returned no interpretable results. Therefore, the number of food frequency categories was redefined using multiple correspondence analysis (MCA) in each food group. In this procedure, the correspondence matrix derived from the contingency table can be decomposed into eigenvalues and eigenvectors, from which the main coordinates of the table lines and columns can be defined. The first two axes of the lines and columns were used in this study as they are the most representative in terms of the association among the variables 22 . Two or three categories were set up, depending on the food group: (1) consumed once or more a week plus consumed sporadically and (2) not consumed; or (1) consumed daily, (2) consumed weekly and (3) consumed sporadically or not consumed. That decision was based on the type of clustering of frequency category coordinates observed on the graphs extracted from the first two axes. After that stage, the percentages in each frequency category were examined and, in cases where a category accounted for less than $1 \%$, it was regrouped with the next most frequent consumption category.

Table 1 shows the composition of the food groups and the frequency categories adopted for each group. Food items that characterized typical preparations and beverages such as chimarrão (mate), caruru (okra, shrimp and nuts), vatapá (spicy shrimp and peanut paste), acarajé (fried shrimp croquette), feijoada (bean stew), Japanese food etc. were eliminated, because they were consumed much less frequently (less than
$2 \%$ ) or not at all in some of the study centers, making it harder to establish patterns. Alcoholic beverages were also eliminated as this study aimed to identify dietary patterns.

\section{- Definition of food subgroups}

\section{a) Step 1}

In this stage, the MCA was used once again, by inspecting the graphs, to indicate how many subgroups were formed.

\section{b) Step 2}

After identifying the number of possible subgroups from the MCA graphs, the vectors of the first two axes, corresponding to the coordinates of the food frequency categories, were extracted. That procedure made it possible to define the number of subgroups by cluster partition analysis (partitioning around medoids, PAM). At this stage, the cluster graphs were examined to ascertain intragroup homogeneity and intergroup heterogeneity, and the silhouette graphs were used to assist in analyzing the cluster quality of the previously established $\mathrm{k}$ groups (the closer to 1 the silhouette value, the better placed those items are in the group). In addition, the silhouette statistic was used as a parameter for defining the number of subgroups, the value desired being in excess of 0.523 . Higher silhouette values indicated better clustering of items in the group. Negative silhouette values indicated that the food item was not appropriately classified in that subgroup and, in these cases, the analyses were repeated to test a different number of subgroups. The MCA, cluster and silhouette graphs for each subgroup are available at http://www.elsa.org. br/artigos.html.

\section{c) Step 3}

In this stage, a function was constructed to classify individuals by identifying the least distance between their coordinate values (extracted on the basis of the first two axes) and the centroid of the subgroup. In cases of subgroups with percentages of less than $1 \%$ (the criterion specified), the stages to define the number of subgroups were reviewed to assure proper definition of the content of each subgroup. From this stage onwards, the individuals were classified as belonging to the subgroups " $\mathrm{x}$ " of the fruits group, "y" of the vegetables group, "w" of the cereals group and so on, for all the food groups shown in Table 1 . The subgroups generated in steps 1 to 3 are shown in Table 2. 
Table 1

Food groups and frequency categories. Brazilian Longitudinal Study of Adult Health (ELSA-Brasil), 2008-2010.

\begin{tabular}{|c|c|c|}
\hline Groups & Foods & Frequency categories \\
\hline $\begin{array}{l}\text { Refined cereals, whole cereals and } \\
\text { tubers and roots }\end{array}$ & $\begin{array}{l}\text { White rice; whole-grain rice; oats, granola and other whole flours; farofa } \\
\text { (cassava flour with complements), cornmeal cuscus; cassava flour and } \\
\text { corn flour; light bread; French rolls, sliced loaf and pita bread; wholemeal } \\
\text { bread; simple cake; salt biscuit (cracker type); sweet biscuit w/o filling; } \\
\text { potato (stewed, boiled or mashed); boiled cassava, yam, sweet potato; } \\
\text { fried potato, cassava, polenta and sweet potato; macaroni; instant } \\
\text { macaroni; and sweetcorn }\end{array}$ & $\begin{array}{l}\text { 1) consumed daily; 2) consumed } \\
\text { weekly; 3) consumed sporadically } \\
\text { or not consumed * }\end{array}$ \\
\hline Confectionery & $\begin{array}{l}\text { Sweets, caramels; cereal bar; sweet biscuit with filling; cake with filling, } \\
\text { tart, trifle; chocolate bar, bonbons, chocolates; chocolate powder, } \\
\text { chocolate drink, cappuccino; milk pudding, milk sweet, mousse; jelly; } \\
\text { jam, fruit sweets; honey, syrup; sweet bread; fruit ice lolly; fruit salad with } \\
\text { complements; and ice cream }\end{array}$ & $\begin{array}{l}\text { 1) consumed weekly or more } \\
\text { often; 2) consumed sporadically } \\
\text { or not consumed }\end{array}$ \\
\hline Milk and dairy products & $\begin{array}{l}\text { Full-cream yoghurt; light yoghurt; full-cream dairy milk; semi-skimmed } \\
\text { dairy milk; skimmed dairy milk; butter; margarine; yellow cheeses; white } \\
\text { cheeses; full-cream cheese spread; and light cheese spread }\end{array}$ & $\begin{array}{l}\text { 1) consumed daily; 2) consumed } \\
\text { weekly; 3) consumed sporadically } \\
\text { or not consumed }\end{array}$ \\
\hline $\begin{array}{l}\text { Red meats, processed meats and } \\
\text { eggs }\end{array}$ & $\begin{array}{c}\text { Boned beef (steak, minced meat and stewed meat); beef on the bone } \\
\text { (rib, oxtail); pork; sausage; light cold meats (turkey sausage, turkey } \\
\text { breast, chicken breast); ham, mortadella, salami; bacon; tripe; liver, offal; } \\
\text { stroganoff; fried egg, omelette, scrambled egg; and boiled and } \\
\text { poached egg }\end{array}$ & $\begin{array}{l}\text { 1) consumed weekly or more } \\
\text { often; 2) consumed sporadically } \\
\text { or not consumed. }\end{array}$ \\
\hline White meats and fish & $\begin{array}{l}\text { Boiled chicken; fried chicken; chicken breast; boiled, baked or grilled fish; } \\
\text { fried fish; shrimp, shellfish; crab, swimming crab; and sardine, tuna }\end{array}$ & \\
\hline Non-alcoholic beverages & $\begin{array}{l}\text { Coffee with sugar; coffee with sweetener; coffee with no sugar; mate with } \\
\text { sugar; mate with sweetener; sugar-free mate; soy extract; soft drinks; light } \\
\text { soft drinks; artificial juice with sugar; artificial juice with sweetener; sugar- } \\
\text { free artificial juice; industrialized juice with sugar; industrialized juice with } \\
\text { sweetener; sugar-free industrialized juice; natural juice with sugar; natural } \\
\quad \text { juice with sweetener; sugar-free natural juice; and coconut water }\end{array}$ & $\begin{array}{l}\text { 1) consumed weekly or more } \\
\text { often; 2) consumed sporadically } \\
\text { or not consumed }\end{array}$ \\
\hline Vegetables & $\begin{array}{l}\text { Zucchini, chayote, eggplant; pumpkin; lettuce; garlic; beetroot; broccoli; } \\
\text { onion; carrot; chicory, watercress, arugula, raw collards, raw spinach, } \\
\text { escarole; braised collards, braised spinach; cauliflower; okra; tomato; } \\
\text { runner beans; vegetable soup }\end{array}$ & $\begin{array}{l}\text { 1) consumed daily; } 2 \text { ) consumed } \\
\text { weekly; 3) consumed sporadically } \\
\text { or not consumed }\end{array}$ \\
\hline Fruit & $\begin{array}{l}\text { Avocado; pineapple; banana; persimmon, jack, pine nut; guava; orange, } \\
\text { tangerine; apple, pear; papaya; mango; watermelon; melon; strawberry; } \\
\text { peach, plum, cashew, kiwi; grape; and fruit salad with no complements }\end{array}$ & $\begin{array}{l}\text { 1) consumed daily; } 2 \text { ) consumed } \\
\text { weekly; 3) consumed sporadically } \\
\text { or not consumed }\end{array}$ \\
\hline Fast food & $\begin{array}{l}\text { Hamburger, cheese puffs, hotdog, popcorn, fried and baked savories, } \\
\text { pizza, mayonnaise, instant soup }\end{array}$ & $\begin{array}{l}\text { 1) consumed daily; 2) consumed } \\
\text { weekly; 3) consumed sporadically } \\
\text { or not consumed }\end{array}$ \\
\hline $\begin{array}{l}\text { Legumes (items examined in } \\
\text { isolation) }\end{array}$ & $\begin{array}{l}\text { Beans (black, red, white, cowpeas etc.) } \\
\text { Lentils, chickpeas and peas } \\
\text { Walnuts, cashew nuts, Brazil nuts, peanuts, almonds and pistachio nuts }\end{array}$ & $\begin{array}{l}\text { 1) consumed daily; 2) consumed } \\
\text { weekly; 3) consumed sporadically } \\
\text { or not consumed }\end{array}$ \\
\hline
\end{tabular}

* Except whole-grain rice, wholemeal bread, light bread, instant pasta, fried potato and polenta, which were categorized as consumed weekly or more often and consumed sporadically or not consumed.

Steps 1 to 3 were not applied for "beans", "other legumes" and "nuts and other grains", because of the small number of items. For these items, the separation of frequency categories identified in the previous stage of the analysis was maintained. 
Description and proportion of food subgroups. Brazilian Longitudinal Study of Adult Health (ELSA-Brasil), 2008-2010.

Group (mean silhouette)/Subgroup (SG)
Silhouette in

subgroup
Proportion

(\%) of

individuals

Refined cereals, whole cereals and tubers and roots (0.52)

SG1. Whole-grain rice consumed daily or weekly and white rice not consumed

SG2. Cereals and tubers, except whole-grain rice, consumed weekly

SG3. Refined cereals consumed daily

SG4. Oats consumed daily and other flours or preparations based on refined flours not consumed

SG5. Potatoes, bread and pastas not consumed

SG6. Cereals, tubers and roots not consumed

SG7. Refined flour preparations consumed daily (cassava flour, pasta, cake)

Confectionery (0.59)

SG1. Confectionery of all kinds not consumed

SG2. Low-calorie confectionery (honey, jam and cereal bar) consumed daily or weekly

SG3. High-calorie confectionery (ice cream, flan, iced cake and other preparations of the group) consumed daily or weekly

Milk and diary products (0.47)

SG1. Skimmed milk and light dairy products consumed weekly

SG2. Full-cream milk and dairy products consumed weekly

SG3. Skimmed milk and light dairy products consumed daily

SG4. White cheese and semi-skimmed milk consumed daily

SG5. Semi-skimmed milk, mix of full-cream dairy products and white cheese consumed weekly

SG6. Full-cream milk and dairy products and yellow cheeses consumed daily

Red and processed meats (0.44)

SG1. Not consumed red meats

SG2. Red meats consumed daily or weekly

White meats and fish (0.50)

SG1. Boiled chicken and fried consumed daily

SG2. Fish and shellfish consumed daily or weekly and chicken weekly

SG3. Chicken breast consumed daily or weekly and other white meats not consumed

Non-alcoholic beverages (0.56)

SG1. Sugary beverages and soft drinks consumed daily or weekly

SG2. Beverages with sweetener and light soft drinks consumed daily or weekly

SG3. Soy-based and sugar-free beverages consumed daily or weekly

SG4. Coconut water consumed daily or weekly and other beverages not consumed

Vegetables (0.60)

$\mathrm{SG} 1$. All vegetables consumed weekly

SG2. Light green vegetables consumed daily

SG3. Vegetables not consumed

SG4. Dark green and orange vegetables consumed daily

SG5. Lettuce, tomato, carrot, other, dark green vegetables consumed daily

SG1. More popular fruit (papaya, apple, orange and banana) consumed daily

SG2. All types of fruit consumed weekly

SG3. Fruit not consumed

SG4. Less popular fruit and fruit salad without complement consumed daily

Fast food (0.47)

SG1. Fast food consumed daily or weekly

Other legumes [chickpeaks, lentils, peas] (item examined in isolation)

SG1. Other legumes consumed daily or weekly

SG2. Other legumes not consumed

Nuts and other grains (item examined in isolation)

SG1. Nuts and other grains consumed daily or weekly

SG2. Nuts and other grains not consumed

$\quad 51.5$

Beans (item examined in isolation)

SG1. All types of bean consumed daily or weekly

48.5

SG2. No consumption

$\begin{array}{ll}- & 95.7 \\ - & 4.3\end{array}$




\section{- Identification of dietary patterns}

\section{a) Step 4}

After identification of the subgroups (treated as new variables that will form part of the pattern), steps 1 to 3 were applied to identify dietary patterns using the same criteria as described above.

The number of patterns was selected by the best graphic separation of the clusters, the best overall silhouette graph and the highest mean silhouette statistic 23 .

This study considered the following sociodemographic characteristics: sex, age group in whole years ( 35 to 44 ; 45 to 54 ; 55 to 64 ; and 65 and over), level of education (incomplete elementary school, elementary school, middle school, higher education and postgraduate education) and states where the ELSA-Brasil Study Centers were located: Bahia, Rio de Janeiro, São Paulo, Minas Gerais, Espírito Santo, and Rio Grande do Sul. The chi-square test was used to ascertain independence among the proportions. The analyses were conducted with the assistance of $\mathrm{R}$ software (v2.15.1), in the RStudio environment (v5.4) and using the FactoMineR and cluster libraries (The R Foundation for Statistical Computing, Vienna Austria; http://www.r-project.org) 24.

\section{Results}

The number of subgroups identified among the food groups ranged from two to seven ( $\mathrm{Ta}$ ble 2). The highest silhouette values were observed for fruits, vegetables, sweets and nonalcoholic beverages.

In the cereals group, the two most frequent subgroups were those comprising refined foods and tubers (SG2 and SG3). The least frequent subgroups were characterized by consumption of whole cereals (SG1) or by non-consumption of potatoes, bread and pastas, cereals tubers and roots (SG5 and SG6). In the milk and dairy products group, the most frequent subgroup (SG4; $38.4 \%$ ) comprised daily consumption of curd cheese and semi-skimmed milk, which may be considered healthier. Meanwhile, the second most frequent was SG6 (27.6\%), characterized by daily consumption of full-cream milk and yellow cheeses. Striking in the non-alcoholic beverages group was the formation of a subgroup (SG4) differentiated by consumption of coconut water, while the others were characterized mainly by the presence or absence of sugar in beverages. Five subgroups were identified in the vegetables group, the most frequent characterized by consumption once a week of some type of vegetable
(SG1), followed by the "no consumption" subgroup (SG3). Similarly, the most frequent subgroups in the fruit group were consumption once a week of all fruit types (SG2) and "no consumption" (SG3) (Table 2).

The cluster that comprised the best separation of groups in the cluster graph was the one with four dietary patterns (Figure 1).

The cluster of the most frequent pattern (45.7\%) can be termed "traditional" in that it includes beans and refined cereals (white rice, for instance) (Table 3). Most individuals in this pattern consumed beans, other legumes, red meats and processed red meat products, white meats and confectionery in general daily or weekly. They consumed milk, fruit and vegetables and refined cereals weekly, and did not consume fast-food.

The second most frequent profile (25.7\%), "fruit and vegetables", grouped individuals whose daily consumption included raw and light green vegetables, fruits, grilled chicken, white cheese and semi-skimmed milk, who consumed coconut water and fast-food daily or weekly and did not consume red meat, beans, refined cereals and confectionery in general.

The third most frequent consumption pattern (24.4\%), "bakery products", comprised daily consumption of refined cereals, bread, biscuits, fried chicken, full-cream milk and dairy products, with no consumption of vegetables, fruit and legumes. The least frequent pattern (4.3\%) in the ELSA-Brasil study population, characterized mainly by consumption daily or weekly of wholegrain cereals, skimmed milk and sugarless or soybased beverages, was termed the "low sugar/low fat" pattern (Table 3).

The "traditional" and particularly the "bakery products" patterns were the most frequent among the men, while the "fruit and vegetables" and "low sugar/low fat" patterns were the most frequent among the women (Table 4). The older the age group the smaller the proportion of the "traditional" pattern and the greater the proportion of the "fruit and vegetables" and "low sugar/ low fat" patterns. In these two latter patterns ("fruit and vegetables" and "low sugar/low fat"), the relative difference between the 35 to 44 and 65 to 74 year age groups was three times or more.

Level of education was found to be inversely related to the "bakery products" pattern. That pattern was five times more frequent among individuals with incomplete elementary education than among those with postgraduate education. The "traditional", "fruit and vegetables" and "low sugar/low fat" patterns were present in strikingly higher proportions among individuals with higher and postgraduate education. In addition, 


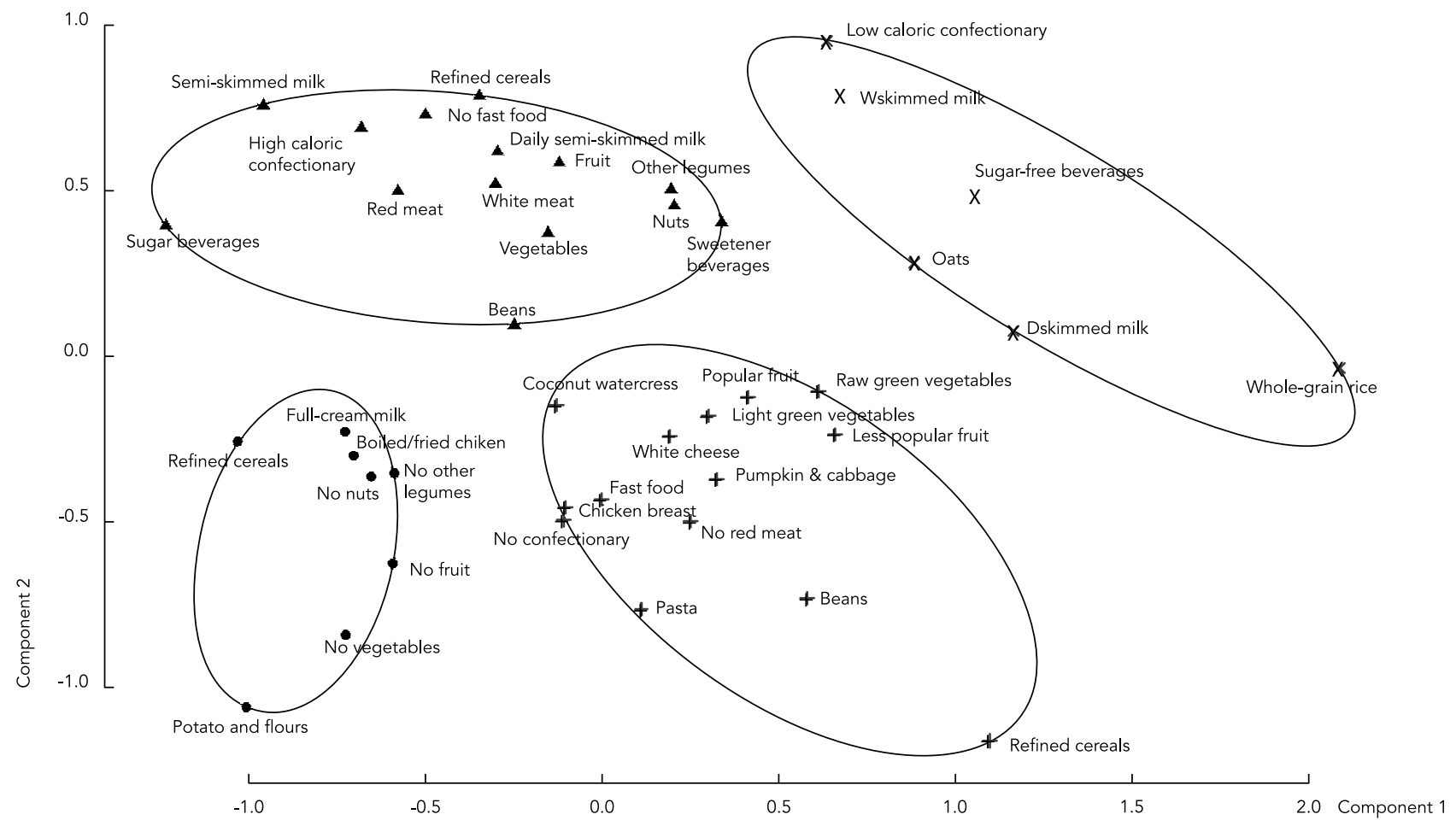

the "low sugar/low fat" pattern was present in nearly twice the proportion of individuals with postgraduate education when compared with those with higher education (Table 4).

Distribution of the patterns differed with the participants' city of residence. When the ELSA Study Centers were compared, it was observed that participants at the São Paulo and Bahia ELSA Study Centers were distributed more homogeneously among the four patterns. Participants at the Minas Gerais, Rio de Janeiro and Rio Grande do Sul ELSA Study Centers displayed the traditional pattern in the highest proportions (approximately $50 \%$ of participants). Minas Gerais, meanwhile, displayed the "fruit and vegetables" pattern in the smallest proportion. Participants at the Espírito Santo ELSA Study Center displayed the "bakery products" pattern in the highest proportion. The "low sugar/low fat" pattern was conspicuous among participants residing in Rio Grande do Sul (8.52\%), where it was twice as frequent as in Bahia (4.36\%) and Rio de Janeiro (4.1\%) (Table 4).

\section{Discussion}

The "traditional" pattern was the most frequent of the four dietary patterns identified. Among women, it was followed by the "fruit and vegetables" pattern and, among men, by the "bakery products" pattern. Regional differences were also observed.

As is usual in nutritional epidemiology, comparisons of our findings with those of previous studies are limited by differences in methods (as regards the questionnaire and the analysis used) to derive and name dietary patterns. In this respect, we have endeavored to identify similarities and differences in relation to the related literature.

Studies from the late 1990s, in São Paulo ${ }^{21}$ and in Brazil's Southeast and Northeast regi-ons 18 , identified the presence of beans or legumes and rice or cereals in the traditional pattern, as do our results. The results of those previous studies showed that meats, milks and dairy products and confectionery were situated in other patterns, 
Table 3

Description and proportion of dietary patterns. Brazilian Longitudinal Study of Adult Health (ELSA-Brasil), 2008-2010.

\begin{tabular}{|c|c|c|}
\hline Pattern (mean silhouette)/Composition & Silhouette of item & Proportion (\%) of individuals \\
\hline "Traditional" (0.43) & & 45.7 \\
\hline Milk and dairy products semi-skimmed consumed weekly & 0.65 & \\
\hline Refined cereals consumed weekly & 0.64 & \\
\hline White meats consumed weekly & 0.63 & \\
\hline Fast food not consumed & 0.61 & \\
\hline Fruit consumed weekly & 0.59 & \\
\hline More energy-dense confectionery consumed daily or weekly & 0.54 & \\
\hline Processed red meats and eggs consumed daily or weekly & 0.52 & \\
\hline Vegetables in general consumed weekly & 0.50 & \\
\hline Semi-skimmed milk and dairy products consumed daily & 0.40 & \\
\hline Nuts consumed daily or weekly & 0.32 & \\
\hline Beans consumed daily or weekly & 0.21 & \\
\hline Other legumes consumed daily or weekly & 0.34 & \\
\hline Beverages with sweeteners consumed daily or weekly & 0.11 & \\
\hline Beverages with sugar consumed daily or weekly & 0.03 & \\
\hline "Fruit and vegetables" (0.42) & & 25.7 \\
\hline Pumpkin and cabbage consumed daily & 0.64 & \\
\hline Processed red meats and eggs not consumed & 0.60 & \\
\hline White cheese and semi-skimmed milk consumed daily & 0.57 & \\
\hline Light green vegetables consumed daily & 0.56 & \\
\hline Beans not consumed & 0.55 & \\
\hline Popular fruit consumed daily & 0.51 & \\
\hline Fast food consumed daily or weekly & 0.42 & \\
\hline Pasta and instant pasta consumed daily & 0.40 & \\
\hline Less popular fruit consumed daily & 0.39 & \\
\hline Raw green vegetables consumed daily & 0.32 & \\
\hline Refined cereals not consumed & 0.28 & \\
\hline Chicken breast consumed daily & 0.25 & \\
\hline Confectionery not consumed & 0.24 & \\
\hline Coconut water consumed daily or weekly & 0.18 & \\
\hline "Bakery products" (0.60) & & 24.4 \\
\hline Nuts and other grains not consumed & 0.68 & \\
\hline Boiled or fried chicken consumed daily & 0.67 & \\
\hline Lentils and other legumes not consumed & 0.62 & \\
\hline Full-cream milk and dairy products consumed daily & 0.60 & \\
\hline Fruit not consumed & 0.59 & \\
\hline Vegetables not consumed & 0.58 & \\
\hline Refined cereals consumed daily & 0.55 & \\
\hline Potato and flours consumed daily & 0.51 & \\
\hline "Low sugar/low fat" (0.34) & & 4.3 \\
\hline Sugar-free and soy-based beverages & 0.52 & \\
\hline Oats consumed daily & 0.36 & \\
\hline Skimmed milk consumed daily & 0.32 & \\
\hline Skimmed milk consumed weekly & 0.31 & \\
\hline Whole-grain rice consumed daily or weekly & 0.28 & \\
\hline Less energy-dense confectionery consumed daily or weekly & 0.22 & \\
\hline
\end{tabular}


Total population and distribution of dietary patterns by sociodemographic variables. Brazilian Longituninal Study of Adult Health (ELSA-Brasil), 2008-2010.

\begin{tabular}{|c|c|c|c|c|c|c|}
\hline \multirow[t]{2}{*}{ Variables } & \multirow{2}{*}{$\begin{array}{c}\text { ELSA-Brasil } \\
\text { population (\%) }\end{array}$} & \multicolumn{4}{|c|}{ Dietary patterns (\%) } & \multirow[t]{2}{*}{ p-value * } \\
\hline & & Bakery products & Traditional & Fruit and vegetables & Low sugar/low fat & \\
\hline Sex & & & & & & $<0.001$ \\
\hline Female & 54.40 & 19.16 & 44.27 & 30.81 & 5.76 & \\
\hline Male & 45.60 & 30.72 & 47.44 & 19.27 & 2.57 & \\
\hline Age group (years) & & & & & & $<0.001$ \\
\hline $35-44$ & 22.06 & 24.39 & 58.31 & 14.67 & 2.64 & \\
\hline $45-54$ & 39.31 & 25.75 & 48.80 & 21.78 & 3.68 & \\
\hline $55-64$ & 28.04 & 23.28 & 37.15 & 33.67 & 5.90 & \\
\hline $65-74$ & 10.59 & 22.68 & 30.56 & 40.83 & 5.92 & \\
\hline Education & & & & & & $<0.001$ \\
\hline Elementary incomplete & 5.92 & 54.61 & 23.26 & 21.57 & 0.56 & \\
\hline Elementary complete & 6.81 & 45.66 & 32.78 & 21.07 & 0.49 & \\
\hline Middle & 34.64 & 32.57 & 45.33 & 20.68 & 1.42 & \\
\hline Higher & 16.00 & 18.68 & 51.08 & 26.32 & 3.93 & \\
\hline Postgraduate & 36.63 & 10.47 & 49.76 & 31.27 & 8.51 & \\
\hline Study Center & & & & & & $<0.001$ \\
\hline Bahia & 13.43 & 27.18 & 38.07 & 30.40 & 4.36 & \\
\hline Espírito Santo & 6.98 & 32.07 & 39.11 & 26.07 & 2.76 & \\
\hline Minas Gerais & 20.62 & 23.59 & 50.56 & 22.63 & 3.22 & \\
\hline Rio de Janeiro & 11.81 & 19.53 & 50.56 & 25.81 & 4.10 & \\
\hline São Paulo & 33.51 & 27.70 & 43.61 & 25.05 & 3.64 & \\
\hline Rio Grande do Sul & 13.65 & 15.30 & 50.28 & 25.91 & 8.52 & \\
\hline
\end{tabular}

* Chi-squared test.

which differs from the results found in the ELSABrasil study population. Although consumption of beans has been observed to decline progressively in the Brazilian population 25 , it is observed in $73 \%$ of homes, making them one of the traditional foods most consumed in Brazil 26. Monteiro et al. 27 and Levy et al. 28 have shown that consumption of red meats and milks is increasing in Brazil, over recent decades, and that frequent consumption particularly of meats denotes high social prestige 29. More recently, Marchioni et al. 13, examining data on Brazilians' food purchases, found pork in the "traditional" pattern, which is similar to our findings. One notable inclusion in our "traditional" pattern is high energy density products (such as cakes and ice creams), unlike what might be expected of that pattern (e.g. fruitbased or homemade confectionery). That result also seems to reflect food practices belonging to a more contemporary "traditional" pattern among Brazilian workers, as these foods reflect an image of modernity 30 . It also aligns with findings in the literature as to the increasing consumption of ultra-processed, ready-to-eat products in Brazil 31.
The second most frequent pattern, "fruit and vegetables", the only one characterized by daily consumption of these food groups, was not identified in previous population-based studies in Brazil. This might be explained by the fact that the ELSA-Brasil study assessed a population of eminently urban workers, who often eat out, with access to weigh-and-pay (a more recent meal pattern in Brazil's dietary culture) and greater daily access to vegetables $28,32,33$. This pattern, which could be considered the "healthiest", is differentiated from the others by more frequent consumption of foods in their natural state. Unexpectedly, this "fruit and vegetables" pattern includes fastfood consumed daily or weekly. The presence of fast-food in this group reinforces the theory according to which apparently "inconsistent" food choices are common and reflect dietary practices influenced by a complex web of factors situated at levels from the macro to the everyday micro level 34 . Choices are thus influenced by dietary culture, cost, availability and marketing, as well as by the palatability of the foods/products and so on 13,35. 
The "bakery products" pattern, often similar to the "fruit and vegetables" pattern, was the most consistent and robust of all the profiles (silhouette $=0.60$ ). Individuals in this group do not consume foods that are protective of health, such as fruit, vegetables and other legumes. The group comprises lower-cost foods and ultra-processed items that are consumed in snacks, and an upward trend is now being observed in such consumption in Brazil 31. This population may have more opportunity to consume vegetables when, for example, eating out at weigh-and-pay restaurants. On the other hand, living in large towns, it faces the problem of lack of time to prepare meals including vegetables at home, instead eating snacks and fast food. Pollan 36 finds that one of the reasons for fruit and vegetables not being consumed daily may be the high cost of such foods and the difficulty of preparing them, given the fast pace of life in large towns.

The least frequent (5\%) was the "low sugar/ low fat" pattern, which can be considered recent in Brazil. No previous study of Brazilian adults has identified a pattern exclusively with these characteristics. This pattern included foods that are rich in fiber (oats and whole grain rice consumed daily), low in fat (skimmed milk consumed daily or weekly) and sugar-free or lowsugar (sugar-free or soy-based beverages consumed daily or weekly). It featured eating habits that were healthier and also restrictive when occurring in isolation, which may originate from professional recommendations for the control of chronic diseases, such as eliminating sugar in cases of diabetes. These health conditions are highly prevalent in Brazil and the media have publicized many recommendations relating to these food items.

While the composition of patterns comprising both healthy and unhealthy foods may represent a challenge in understanding how dietary choices are combined, on the other hand, the associations observed between patterns and sociodemographic characteristics suggest that the patterns identified are consistent and give them "face validity". The distribution of those patterns by sociodemographic characteristics of the ELSA-Brasil study population is similar to recent findings in the Brazilian literature. Although using different methods, Gimeno et al. 37 observed greater frequency of the "healthy" pattern among women and older adults, while Marchioni et al. 13 and Arruda et al. 38 observed higher frequencies of the traditional pattern among men and among individuals with less schooling.

The "traditional" and "bakery products" patterns were more frequent among men and the younger age groups, which are known to be less concerned with health 39,40,41. Meanwhile, the "fruit and vegetables" and "low sugar/low fat" patterns were more frequent among women, confirming the results of other studies in which consumption of healthy foods is reported more frequently by women and older adults 38,42 . Probably because of their greater concern with beauty, health and more frequent recourse to health services, these two sub-groups are more likely to be following specific recommendations for control of diabetes, dyslipidemias and weight control 43,44,45. Also, older adults may display physiological intolerances, such as reduced digestive capacity, which lead to reduced consumption of red meats, beans and other legumes 26 .

Level of education was directly related to frequency of the "fruit and vegetables" and "low sugar/low fat" consumption pattern, confirming the findings of other studies 46,47 that individuals with more education display "healthier" consumption patterns. This association may be explained both by greater purchasing power and by the likelihood of their occupations' favoring healthier lifestyles. What is notable is that the "bakery products" pattern (which excludes consumption of fruit and vegetables) accounts for nearly one quarter of the ELSA-Brasil population (civil servants in tenured employment), and more than $50 \%$ of the individuals with the lowest levels of education in that population. Accordingly, we believe that, together with the higher cost of fruit and vegetables, dietary culture exerts an important role in selection of these foods. Claro \& Monteiro 48 write that little headway has been made in Brazil in applying public policies to reduce the cost of fruit and vegetables.

As it was not possible to compare the distribution of dietary patterns by study center for lack of previous studies at the same locations, we compared our results with data from the Brazilian National Dietary Survey (INA) ${ }^{49}$, with a view to identifying whether the foods present in the patterns in our study displayed similar frequency distributions by region of Brazil. We observed that the distribution of the patterns by study center coincided partly with this national dietary survey, demonstrating, to some extent, the permanence of regional dietary culture. For example, the traditional pattern was more frequent among participants in Rio Grande do Sul (South region), and in Rio de Janeiro and Minas Gerais (Southeast region). The INA also found that foods such as meats, processed meats and beans, which form part of this pattern, were most frequently consumed in Brazil's South and Southeast regions. In Espírito Santo and São Paulo (Southeast region) and Bahia (Northeast region) a higher proportion of consumption was found in the "bakery 
products" pattern, involving mainly refined cereals (bread, pastas, flour and potatoes) and fullcream milk and dairy products, which may relate to consumption of snacks that replace meals or even to their being less expensive foods. In addition, the use of flour in preparations typical of Espírito Santo and Bahia would also explain the presence of such foods in this pattern. The "diet/ light" pattern, which was most frequent in Rio Grande do Sul, was also observed in the INA findings on consumption of skimmed milk and less energy-dense confectionery, which was greater in the South region 49.

Errors inherent to the process of measuring food consumption that may have occurred include overestimating consumption of certain food groups. Although that is a possibility, this study had the advantage of using a pretested questionnaire, whose validity had been estimated and which was subjected to a strict quality control process 19 . Another limitation is the possibility of classification errors in the patterns, given that this technique classifies individuals into mutually exclusive patterns. However, our objective was to identify typical behaviors, which characterize the main aspects of behaviors typified in individuals, which is a potential use of the analysis employed 22 .

The strengths of this study reside in the explicit description of all the stages involved. Systematic reviews on the subject have criticized studies for the large numbers of steps that depend on researchers' choices and for a failure to state explicitly the criteria used at those stages 5,50 . On the other hand, little has been done in Brazil to problematize the choice of multivariate analysis as a method for defining dietary patterns, the exception being Castro et al. 51. The techniques most often used (factorial analysis and principal component analysis) presuppose the use of continuous variables. Most studies, however, say little explicitly about the characteristics of the distributions calculated in the studies to derive the patterns. In our study, we opted to analyze consumption frequency categories, instead of using the sum of weight in grams or energy consumed, on the assumption that frequency represents more robust information on the dietary habits of the population studied. The reason is it avoids the errors related to the process of converting to weight and estimating nutrients 52 .

In all, four dietary patterns were identified in the study population, the "traditional" pattern being most frequent. For the first time in a Brazilian study, a pattern was identified that comprised sugar-free and low-fat and low-sugar foods and beverages, seeming to demonstrate a new set of dietary practices among a Brazilian working population residing in large cities. These results demonstrate the complexity of understanding one of the most significant health exposures, especially regarding the impact on public policy guidelines and programmes. The relation to sociodemographic variables showed subgroups with higher proportions of healthier patterns (women, more educated individuals and older individuals) and less healthy patterns (men, younger individuals and individuals with less education), alerting to the need for measures to encourage and support healthy diet for these groups. It seems that robust measures, particularly by the state, are needed to help to build and spread a culture of healthy diets in Brazilian society, as has been done to develop an anti-smoking culture. Less privileged population groups, both in the general population and among working people, should be considered as priorities. The current dietary guidelines for the Brazilian population serve to improve the quality of diet, but broad measures (such as taxation and regulation of ultra-processed products; media campaigns; professional recycling and capacitybuilding) are still necessary. Progress must be made in this regard in order to interrupt the rising rates of illness and death from chronic diseases in Brazil. Lastly, prospective monitoring of this population will make it possible to evaluate how these patterns impact on the development of diabetes and cardiovascular diseases. 


\section{Contributors}

L. O. Cardoso participated on the study design, data analysis, interpretation and discussion of results and writing the article. M. S. Carvalho contributed on the study design, statistical modeling, interpretation and discussion of results, writing and revising the manuscript. O. G. Cruz participated on the data analysis, interpretation and discussion of results, revision of article. C. Melere collaborated on the data collection, writing and revising the article. V. C. Luft contributed on the interpretation of results; article writing and critical review. M. C. B. Molina, I. M. Benseñor and C. P. Faria participated on the data collection, interpretation and discussion of results, writing and revision of article. S. M. A. Matos contributed on the interpretation and discussion of results, writing and critical review of the manuscript. M. J. M. Fonseca and R. H. Griep participated on the research design, analysis and interpretation of data and critical review of the manuscript. D. Chor contributed on the study design, interpretation and discussion of results, writing and revising the article.

\section{References}

1. Scrinis G. Nutritionism: the science and politics of dietary advice. New York: Columbia University Press; 2013.

2. Departamento de Atenção Básica, Secretaria de Atenção à Saúde, Ministério da Saúde. Guia alimentar para a população brasileira. 2a Ed. Brasília: Ministério da Saúde; 2014.

3. World Health Organization. Preparation and use of food-based dietary guidelines: report of a joint FAO/WHO consultation. Geneva: World Health Organization; 1998. (WHO Technical Report Series, 880).

4. Paeratakul S, Popkin BM, Kohlmeier L, Hertz-Picciotto I, Guo X, Edwards LJ. Measurement error in dietary data: implications for the epidemiologic study of the diet-disease relationship. Eur J Clin Nutr 1998; 52:722-7.

5. Hu FB. Dietary pattern analysis: a new direction in nutritional epidemiology. Curr Opin Lipidol 2002; 13:3-9.

6. Popkin BM, Adair LS, Ng SW. Global nutrition transition and the pandemic of obesity in developing countries. Nutr Rev 2012; 70:3-21.

\section{Acknowledgments}

The authors thank the ELSA-Brasil participants who agreed to take part in this study. The authors also thank Paulo Cesar Castro Junior for his contributions during the writing of this paper. The ELSA-Brasil study was supported by the Science and Technology Departmente of the Brazilian Ministry of Health and the Brazilian Ministry of Science and Technology (FINEP - grants 01060010.00 RS, 01060212.00 BA, 01060300.00 ES, 01060278.00 MG, 01060115.00, 01060071.00 RJ) and the Brazilian National Research Council. The funders had no role in study design, data collection and analysis, decision to publish, or preparation of the manuscript.
7. Monteiro CA, Moubarac JC, Cannon G, Ng SW Popkin B. Ultra-processed products are becoming dominant in the global food system: Obes Rev 2013; 14 Suppl 2:21-8.

8. Perrin AE, Dallongeville J, Ducimetière $\mathrm{P}, \mathrm{Ru}$ idavets JB, Schlienger JL, Arveiler D. Interactions between traditional regional determinants and socio-economic status on dietary patterns in a sample of French men. Br J Nutr 2005; 93:109-14.

9. Alves ALS, Olinto MTA, Costa JSD, Bairros FS, Balbinotti MAA. Padrões alimentares de mulheres adultas residentes em área urbana no sul do Brasil. Rev Saúde Pública 2006; 40:865-73.

10. Fisberg RM, Morimoto JM, Slater B, Barros MBA, Carandina L, Goldbaum M. Dietary quality and associated factors among adults living in the state of São Paulo, Brazil. J Am Diet Assoc 2006; 106:2067-72.

11. Togo P, Osler M, Sørensen TIA, Heitmann BL. A longitudinal study of food intake patterns and obesity in adult Danish men and women. Int J Obes Relat Metab Disord 2004; 28:583-93. 
12. Wakimoto P, Block G. Dietary intake, dietary patterns, and changes with age: an epidemiological perspective. J Gerontol A Biol Sci Med Sci 2001; 56(Spec No 2):65-80.

13. Marchioni DM, Claro RM, Levy RB, Monteiro CA. Patterns of food acquisition in Brazilian households and associated factors: a population-based survey. Public Health Nutr 2011; 14:1586-92.

14. Aquino EML, Barreto SM, Benseñor IM, Carvalho MS, Chor D, Duncan BB. Brazilian Longitudinal Study of Adult Health (ELSA-Brasil): objectives and design. Am J Epidemiol 2012; 175:315-24.

15. Schmidt MI, Duncan BB, Mill JG, Lotufo PA, Chor D, Barreto SM. Cohort profile: Longitudinal Study of Adult Health (ELSA-Brasil). Int J Epidemiol 2015; 44:68-75.

16. Chor D, Alves MGM, Giatti L, Cade NV, Nunes MA, Molina MCB, et al. Questionário do ELSA-Brasil: desafios na elaboração de instrumento multidimensional. Rev Saúde Pública 2013; 47:27-36.

17. Schmidt MI, Griep RH, Passos VM, Luft VC, Goulart AC, Menezes GMS. Estratégias e desenvolvimento de garantia e controle de qualidade no ELSABrasil. Rev Saúde Pública 2013; 47:105-12.

18. Sichieri R, Everhart JE. Validity of a Brazilian food frequency questionnaire against dietary re calls and estimated energy intake. Nutr Res 1998; 18:1649-59.

19. Molina MCB, Faria CP, Cardoso LO, Drehmer M, Velasquez-Meléndez JG, Gomes ALC. Diet assessment in the Brazilian Longitudinal Study of Adult Health (ELSA-Brasil): development of a food frequency questionnaire. Rev Nutr 2013; 26:167-76.

20. Molina MCB, Benseñor IM, Cardoso LO, Velasquez-Meléndez G, Drehmer M, Pereira TSS. Reprodutibilidade e validade relativa do Questionário de Frequência Alimentar do ELSA-Brasil. Cad Saúde Pública 2013; 29:379-89.

21. Marchioni DML, Latorre MRDO, Eluf-Neto J, Wünsch-Filho V, Fisberg RM. Identification of dietary patterns using factor analysis in an epidemiological study in São Paulo. São Paulo Med J 2005; 123:124-7.

22. Hair JF. Multivariate data analysis. Upper Saddle River: Prentice Hall; 2010.

23. Rousseeuw PJ. Silhouettes: a graphical aid to the interpretation and validation of cluster analysis. J Comput Appl Math 1987; 20:53-65.

24. Lê S, Josse J, Husson F. FactoMineR: an R package for multivariate analysis. J Stat Softw 2008; 25:1-18.

25. Levy-Costa RB, Sichieri R, Pontes NS, Monteiro CA. Household food availability in Brazil: distribution and trends (1974-2003). Rev Saúde Pública 2005; 39:530-40

26. Souza AM, Pereira RA, Yokoo EM, Levy RB, Sichieri R. Alimentos mais consumidos no Brasil: Inquérito Nacional de Alimentação 2008-2009. Rev Saúde Pública 2013; 47:190-9.

27. Monteiro CA, Mondini L, Costa RB. Mudanças na composição e adequação nutricional da dieta familiar nas áreas metropolitanas do Brasil (19881996). Rev Saúde Pública 2000; 34:251-8.

28. Levy RB, Claro RM, Mondini L, Sichieri R, Monteiro CA. Regional and socioeconomic distribution of household food availability in Brazil, in 20082009. Rev Saúde Pública 2012; 46:6-15.
29. Ribeiro CDSG. O consumo da carne no Brasil: entre valores socioculturais e nutricionais. Demetra: Alimentação, Nutrição \& Saúde 2013; 8:425-38.

30. Fischler C. Attitudes towards sugar and sweetness in historical and social perspective. In: Dobbing J, editor. Sweetness. London: Springer London; 1987. p. 83-98.

31. Martins APB, Levy RB, Claro RM, Moubarac JC, Monteiro CA. Participação crescente de produtos ultraprocessados na dieta brasileira (1987-2009). Rev Saúde Pública 2013; 47:656-65.

32. Carús JP, França GVA, Barros AJD. Local e tipo das refeições realizadas por adultos em cidade de médio porte. Rev Saúde Pública 2014; 48:68-74.

33. Santos MV, Proença RPC, Fiates GMR, Calvo MCM. Os restaurantes por peso no contexto de alimentação saudável fora de casa. Rev Nutr 2011; 24:641-9.

34. Glanz K, Sallis JF, Saelens BE, Frank LD. Healthy nutrition environments: concepts and measures. Am J Health Promot 2005; 19:330-3.

35. Caspi CE, Sorensen G, Subramanian SV, Kawachi I. The local food environment and diet: a systematic review. Health Place 2012; 18:1172-87.

36. Pollan M. Cooked: a natural history of transformation. New York: The Penguin Press; 2013.

37. Gimeno SGA, Mondini L, Moraes SA, Freitas ICM. Padrões de consumo de alimentos e fatores associados em adultos de Ribeirão Preto, São Paulo, Brasil: Projeto OBEDIARP. Cad Saúde Pública 2011; 27:533-45.

38. Arruda SP, Silva AA, Kac G, Goldani M, Bettiol H, Barbieri M. Socioeconomic and demographic factors are associated with dietary patterns in a cohort of young Brazilian adults. BMC Public Health 2014; 14:654.

39. Gomes R, Nascimento EF, Araújo FC. Por que os homens buscam menos os serviços de saúde do que as mulheres? As explicações de homens com baixa escolaridade e homens com ensino superior. Cad Saúde Pública 2007; 23:565-74.

40. Costa-Júnior FM, Maia ACB. Concepções de homens hospitalizados sobre a relação entre gênero e saúde. Psicol Teor Pesqui 2009; 25:55-63.

41. Lima-Costa MF. A escolaridade afeta, igualmente, comportamentos prejudiciais à saúde de idosos e adultos mais jovens? Inquérito de Saúde da Região Metropolitana de Belo Horizonte, Minas Gerais, Brasil. Epidemiol Serv Saúde 2004; 13:201-8.

42. Malta DC, Iser BPM, Claro RM, Moura L, Bernal RTI, Nascimento AF. Prevalência de fatores de risco e proteção para doenças crônicas não transmissíveis em adultos: estudo transversal, Brasil, 2011. Epidemiol Serv Saúde 2013; 22:423-34.

43. Bays HE, Bazata DD, Fox KM, Grandy S, Gavin 3rd JR; SHIELD Study Group. Perceived body image in men and women with type 2 diabetes mellitus: correlation of body mass index with the figure rating scale. Nutr J 2009; 8:57.

44. Adamson J, Ben-Shlomo Y, Chaturvedi N, Donovan J. Ethnicity, socio-economic position and gender: do they affect reported health-care seeking behaviour? Soc Sci Med 2003; 57:895-904.

45. Zhao G, Ford ES, Li C, Mokdad AH. Weight control behaviors in overweight/obese U.S. adults with diagnosed hypertension and diabetes. Cardiovasc Diabetol 2009; 8:13. 
46. Lenz A, Olinto MTA, Dias-da-Costa JS, Alves AL, Balbinotti M, Pattussi MP, et al. Socioeconomic, demographic and lifestyle factors associated with dietary patterns of women living in Southern Brazil. Cad Saúde Pública 2009; 25:1297-306.

47. Langsetmo L, Poliquin S, Hanley DA, Prior JC, Barr $\mathrm{S}$, Anastassiades T. Dietary patterns in Canadian men and women ages 25 and older: relationship to demographics, body mass index, and bone mineral density. BMC Musculoskelet Disord 2010; 11:20.

48. Claro RM, Monteiro CA. Family income, food prices, and household purchases of fruits and vegetables in Brazil. Rev Saúde Pública 2010; 44:1014-20.

\section{Resumo}

Foi analisado o consumo alimentar de 15.071 servidores públicos de seis cidades brasileiras participantes da linha de base do Estudo Longitudinal de Saúde do Adulto (ELSA-Brasil, 2008-2010), com o objetivo de identificar os padrões alimentares e sua relação com variáveis sociodemográficas. Foram aplicadas análise de correspondência múltipla e cluster. Os quatro padrões identificados e suas respectivas frequências foram: "tradicional" (48\%); "frutas e hortaliças" (25\%); "pastelaria" (24\%); e "diet/light" (5\%) Os padrões "tradicional" e "pastelaria" foram mais frequentes entre homens, indivíduos mais jovens e de menor escolaridade. Por outro lado, os padrões "frutas e hortaliças" $e$ "diet/light" foram mais frequente entre mulheres, indivíduos mais velhos e de maior escolaridade. Nossos achados mostram a inclusão de novos itens no padrão "tradicional" e o aparecimento do padrão "low sugar low fat" entre os hábitos alimentares de trabalhadores brasileiros, e sinalizam diferenças sociodemográficas e regionais.

Comportamento Alimentar; População Urbana; Análise Multivariada; Adulto
49. Instituto Brasileiro de Geografia e Estatística. Pesquisa de Orçamentos Familiares, 2008-2009. Rio de Janeiro: Instituto Brasileiro de Geografia e Estatística; 2010.

50. Togo P, Osler M, Sørensen TI, Heitmann BL. Food intake patterns and body mass index in observational studies. Int J Obes Relat Metab Disord 2001; 25:1741-51.

51. Castro MA, Baltar VT, Selem SS'AC, Marchioni DML, Fisberg RM. Empirically derived dietary patterns: interpretability and construct validity according to different factor rotation methods. Cad Saúde Pública 2015; 31:298-310.

52. Willett W. Nutritional epidemiology. New York: Oxford University Press; 1998.

\section{Resumen}

Se analizó el consumo alimenticio de 15.071 empleados públicos de seis ciudades brasileñas, participantes de la línea de base del Estudio Longitudinal de Salud del Adulto (ELSA-Brasil, 2008-2010), con el objetivo de identificar los patrones alimenticios y su relación con variables sociodemográficas. Se aplicó un análisis de correspondencia múltiple y clúster. Los cuatro patrones identificados y sus respectivas frecuencias fueron: "tradicional" (48\%); "frutas y hortalizas" (25\%); "pastelería" (24\%); y "diet/light" (5\%). Los patrones "tradicional" $y$ "pastelería" fueron más frecuentes entre hombres, individuos más jóvenes y de menor escolaridad. Por otro lado, los patrones "frutas y hortalizas" $y$ "diet/light" fueron más frecuentes entre mujeres, individuos más viejos y de mayor escolaridad. Nuestros hallazgos muestran la inclusión de nuevos ítems en el patrón "tradicional" y la aparición del padrón "low sugar/low fat" entre los hábitos alimenticios de trabajadores brasileños, y señalan diferencias sociodemográficas y regionales.

Conducta Alimentaria; Población Urbana; Análisis Multivariante; Adulto
Submitted on 27/Apr/2015

Final version resubmitted on 31/Aug/2015

Approved on 15/Oct/2015 